\title{
Physical activity of individuals with Parkinson's in social isolation before and during the pandemic COVID-19
}

\section{Atividade física de indivíduos com doença de Parkinson em isolamento social antes e durante a pandemia de COVID-19}

\section{AUTHOR'S \\ Jéssica Amaro Moratelli ${ }^{1}$ (D) \\ Anelise Sonza ${ }^{2}$ (iD \\ Aline Nogueira Haas ${ }^{3}$ \\ Elren Passos-Monteiro 4 (iD \\ Clynton Lourenço Corrêa ${ }^{5}$ (D) \\ Leonardo Alexandre Peyré-Tartaruga ${ }^{3}$ (D) \\ Marcela dos Santos Delabary ${ }^{3}$ (D) \\ Adriana Coutinho de Azevedo Guimarães ${ }^{1}$ (iD \\ 1 Universidade do Estado de Santa Catarina, \\ Departamento de Educação Física, Florianópolis, \\ Santa Catarina, Brasil. \\ 2 Universidade do Estado de Santa Catarina, \\ Departamento de Fisioterapia, Florianópolis, Santa \\ Catarina, Brasil. \\ 3 Universidade Federal do Rio Grande do Sul, \\ Departamento de Ciências do Movimento \\ Humano, Porto Alegre, Rio Grande do Sul, Brasil. \\ 4 Universidade Federal do Pará, Departamento de \\ Educação Física, Belém, Pará, Brasil. \\ 5 Universidade Federal do Rio de Janeiro, \\ Departamento de Fisioterapia, Rio de Janeiro, \\ Brasil.}

\section{CORRESPONDING}

Jéssica Moratelli

jessica.moratelli@hotmail.com

Rua Pascoal Simone, 358 - Coqueiros, Florianópolis, Santa Catarina, Brazil.

ZIP CODE: 88080-350.

\section{DOI}

$10.12820 /$ rbafs. $26 \mathrm{e} 0237$

\section{(cc) BY}

This work is licensed under a Creative Commons Attribution 4.0 International License.

\begin{abstract}
The world has been hit by a pandemic caused by the new coronavirus (COVID-19), which has resulted in government recommendations and measures including social isolation to reduce the spread of the disease. In view of these recommendations, there were drastic changes in lifestyle, impacting the physical and mental health of men and women. Thus, this study aimed to investigate the practice of physical activity, according to sex, in individuals with Parkinson's disease in social isolation before and during the COVID-19 pandemic. Cross-sectional observational study, based on an online questionnaire validated for individuals with Parkinson's disease PAFPA/COVID19, in which 156 individuals of both sexes and degrees of the disease (I to V) were allocated, with a mean age of $63.70 \pm 11.00$ years and from different Brazilian regions. Chi-square, Fisher's exact and binary logistic regression tests were used. It is observed that $92 \%$ of the participants were in social isolation, which caused negative effects on the level of physical activity of the participants, even though most of them doing physical activity online. In addition, it was found that those who participated in specific exercise programs for Parkinson's disease, are less likely to be insufficiently active, as well as individuals who receive online guidance. Although social isolation is a necessary measure to combat COVID-19, the results show a negative effect of this social isolation on the parameters of physical activity in this population in different regions of Brazil. This suggests that better strategies for health promotion in order to increase levels of physical activity at home are necessary to reduce the physical inactivity lifestyle during the pandemic, in order to prevent diseases associated with social isolation and physical inactivity.
\end{abstract}

Keywords: Covid-19; Parkinson's disease; Physical activity; Social isolation.

RESUMO

O mundo foi atingido por uma pandemia causada pelo novo coronavírus (COVID-19), que resultou em recomendaçôes e medidas governamentais, incluindo isolamento social para reduzir a disseminação da doença. Diante dessas recomendaçôes, ocorreram mudanças drásticas no estilo de vida, impactando na saúde física e mental de homens e mulheres. Assim, este estudo teve como objetivo investigar a prática de atividade física, segundo o sexo, em individuos com doença de Parkinson em isolamento social antes e durante a pandemia de COVID-19. Estudo observacional transversal, baseado em questionário online validado para indivíduos com doença de Parkinson PAFPA/COVID19, no qual foram avaliados 156 individuos de ambos os sexose graus da doença (I ao V), com média de idade de 63,70 $\pm 11,00$ anos e de diferentes regiöes brasileiras. Foram utilizados os testes Qui-quadrado, exato de Fisher e a regressão logística binária. Observa-se que $92 \%$ dos participantes encontravam-se em isolamento social, o que causou repercussöes negativas no nivel de atividade física dos participantes, embora a maioria realizasse atividade física online. Além disso, verificou-se que aqueles que participaram de programas de exercícios especificos para a doença de Parkinson, tiveram menor probabilidade de serem insuficientemente ativos, assim como os indivíduos que recebem orientação online. Embora o isolamento social seja uma medida necessária para combater a COVID-19, os resultados mostram um efeito negativo desse isolamento social sobre os parâmetros de atividade física dessa população em diferentes regiöes do Brasil. Isso sugere que melhores estratégias de promoção da saúde para aumentar os níveis de atividade física no domicilio são necessárias para reduzir o inatividade física durante a pandemia, a fim de prevenir doenças associadas ao isolamento social e inatividade física.

Palavras-chave: Covid-19; Doença de Parkinson; Atividade física; Isolamento social.

\section{Introduction}

The world population was surprised, in late 2019, by the disease COVID-19, caused by the new coronavirus (SARS-CoV-2) ${ }^{1}$. COVID-19 causes respiratory 
disorders that can range from no symptoms (asymptomatic) to fever, cough, dyspnea and can progress to severe pneumonia, leading to death ${ }^{2}$. Currently, the COVID-19 pandemic affects 188 countries and according to $\mathrm{WHO}$, it records 5,145,002 deaths until November 30, 20213. In Brazil, until November 30, 2021, 22.084.749 confirmed cases and 614.376 deaths were recorded by COVID-19, increasing the number of cases each day ${ }^{3,4}$. The highest mortality rates are in the older adults and those who have associated comorbidities or chronic diseases such as Parkinson's disease (PD) due to the immune system response of these people being different when compared to younger populations ${ }^{5}$.

In order to prevent the spread of the disease, measures of isolation and social detachment have been adopted in several countries in the world, such as the cancellation of public transport, restrictions on contact and leaving the house, closing schools, university, commerce, compulsory in the use of masks, alcohol gel, among other measures, totally changing people's routine ${ }^{6}$. Social isolation and detachment can have adverse short, medium and long-term consequences in individuals with PD, as they suffer deterioration in social interaction and in the motor and non-motor aspects of the disease, which in turn contribute to disability. In addition, restrictions on outpatient access to adjust antiparkinsonian medication during the COVID-19 pandemic may increase stress levels ${ }^{7,8}$. This results in the worsening of motor symptoms, especially, tremor, bradykinesia and freezing of gait, as well as increased anxiety, depression, worsening sleep quality and physical inactivity ${ }^{9,10}$.

In turn, numerous benefits of physical activity (PA) in individuals with PD are reported, with improvement in motor symptoms, such as balance, tremor, freezing of gait, postural instability, as well as in non-motor symptoms, such as cognition, anxiety, sleep disorders, depression ${ }^{11,12}$. However, the practice of PA in general, such as rehabilitation programs, social groups, physical therapy, speech therapy, public parks, must be adjusted to this new context of social isolation, in which individuals with $\mathrm{PD}$ are not attending in person, due to the high risk of high risk of disease infection ${ }^{10}$.

An alternative found at that time was to promote the practice of PA in the home environment online ${ }^{10,13}$. The proposal for online PA practice is being forwarded by teachers in a safe and monitored manner, including balance activities, muscle strengthening, stretching, dancing, Pilates, yoga, which can be performed in a small space with little use of materials and equipment ${ }^{14}$.
The technologies used vary from online classes, videos and applications that encourage the practice of $\mathrm{PA}$, and these have been used in the older adults and individuals with PD before the pandemic with positive results ${ }^{15,16}$. However, it is important to investigate whether during the COVID-19 pandemic individuals with PD can perform PA remotely (understanding the proposed activity and handling the technologies) in addition to the feeling of security during PA practice without face-to-face monitoring. It is still relevant to verify the adherence of PA practice by comparing the sexes in order to, in the future, verify the applicability of these classes together with the activities in person. Thus, the objective of this study was to investigate the practice of PA, according to sex, in individuals with $\mathrm{PD}$ in social isolation before and during the COVID-19 pandemic.

\section{Methods}

This was an observational cross-sectional study through an online self-administered questionnaire survey. This instrument was validated for individuals with PD and was delivered through social media. The data collection occurred from 12th May to 21th May 2020. Ethical approval was obtained from School of Physical Education, Physical Therapy and Dance of the Federal University of Rio Grande do Sul (CAAE 33547920.9.0000.5347).

Individuals with PD from the Brazilian territory that usually perform PA under supervision in universities, outreach projects and PD groups and associations were invited to participate in this study. Initially, the teachers responsible for the extension projects for people with Parkinson's disease in Brazil were contacted. Subsequently, the responsible professors forwarded the contact of the main researcher to those interested.

After a brief explanation of the consent form, the individuals with PD who agreed to participate were included. Inclusion criteria were individuals of both sexes, aged over 50 years and clinically diagnosed with PD according to London Brain Bank criteria. Individuals with other types of diseases concomitant with Parkinson's were excluded.

Personal and clinical information: regarding age, sex, marital status, degree of disease, education, presence of clinically diagnosed diseases, use of medication and anthropometric measurements (BMI).

We developed the Physical activity before and during COVID-19 social isolation in people with Parkinson's disease (PAFPA/COVID19) to assess the levels 
of PA and mental health impact in individuals with PD before and during the confinement due to the COVID-19 pandemic. For this survey development, a seven-step scale design proposed by Artino et al. ${ }^{17}$ was followed. The validity followed the study of Sá-Caputo et al. ${ }^{18}$ and a panel of 11 experts were invited to participate and test-retest reliability of this instrument were calculated. The tool was divided into three sections, (I) Subjects characterization with sociodemographic, anthropometric and health status questions; (II) Physical activity and mental health before COVID-19; and (III) Physical activity and mental health during COVID-19 pandemic. The questions types were open-ended, closed-ended, and Likert scales ${ }^{20}$.

For the data collection procedure, the questionnaire was distributed through the Brazilian territory by social media (WhatsApp, Facebook, Messenger), and email for PD individuals that usually perform PA under supervision in universities, community projects and PD groups and associations.

The sample size calculation was performed using the $G^{*}$ Power 3.1.9.2 software, with an effect size of 0.38 , a significance level of $5 \%$, a test power of $95 \%$, with no sample loss being predicted, thus, 160 individuals with PD were expected.

The data were analyzed using the IBM SPSS version 20.0 statistical package. To verify an association between general information and PA between genders, the Chi-Squared and Fisher's Exact Tests were used. To verify the relationship between the level of PA and the variables related to the online PA practice during the COVID-19 pandemic, the crude and binary adjusted logistic regression was used. For the adjusted analysis, only variables with $\mathrm{p}<0.20$ in the crude analysis were included. The significance level of 5\% was adopted.

\section{Results}

A total of 156 individuals with PD diagnostic, mean age of $63.7 \pm 11.00$ years, from different degrees of the disease ( $\mathrm{I}$ to $\mathrm{V}$ ) and from different Brazilian regions were evaluated, with the following distribution: South $(n=90)$, Southeast $(n=41)$, North $(n=17)$, Northeast $(n=4)$ and Midwest $(n=4)$.

Table 1 shows the main characteristics of the participants according to gender, with the sample being $50 \%$ female. It can be seen that the majority are married, with emphasis on the male gender $(p=0.003)$. For the most part, both sexes maintained their income during the pandemic and $92 \%$ remained in social iso- lation. According to the participants, tremor and stiffness were considered the symptoms of PD that most disturb them in this period of social isolation.

Table 1 - Sociodemographic data and general characteristics of individuals with PD according to sex.

\begin{tabular}{|c|c|c|c|c|}
\hline Variables & $\begin{array}{c}\text { Total } \\
(\mathrm{n}=156) \\
\mathrm{n}(\%)\end{array}$ & $\begin{array}{c}\text { Female } \\
(\mathrm{n}=78) \\
\mathrm{n}(\%)\end{array}$ & $\begin{array}{c}\text { Male } \\
(\mathrm{n}=78) \\
\mathrm{n}(\%)\end{array}$ & $\mathrm{p}$ value \\
\hline Marital status & & & & $0.003^{*}$ \\
\hline Single & $16(10.3)$ & $12(15.4)$ & $4(5.1)$ & \\
\hline Married/Stable relationship & $101(64.7)$ & $41(52.6)$ & $60(76.9)$ & \\
\hline Widowed & $16(10.3)$ & $13(16.7)$ & $3(3.8)$ & \\
\hline Divorced/Separated & $23(14.7)$ & $12(15.4)$ & $11(14.1)$ & \\
\hline Education & & & & $0.089^{*}$ \\
\hline Elementary school & $30(19.2)$ & $21(26.9)$ & $9(11.5)$ & \\
\hline High school & $59(37.8)$ & $25(32.1)$ & $34(43.6)$ & \\
\hline University education & $40(25.6)$ & $20(25.6)$ & $20(25.6)$ & \\
\hline Postgraduate & $27(17.3)$ & $12(15.4)$ & $15(19.2)$ & \\
\hline Income before pandemic & & & & $0.140^{* *}$ \\
\hline Up to 2 minimum wages & $68(43.6)$ & $41(52.6)$ & $27(34.6)$ & \\
\hline 3 to 4 minimum wages & $42(26.9)$ & $20(25.6)$ & $22(28.2)$ & \\
\hline 5 to 10 minimum wages & $34(21.8)$ & $12(15.4)$ & $22(28.2)$ & \\
\hline 11 to 20 minimum wages & $8(5.1)$ & $4(5.1)$ & $4(5.1)$ & \\
\hline Above 20 minimum wages & $4(2.6)$ & $1(1.3)$ & $3(3.8)$ & \\
\hline Income in the pandemic & & & & $0.217^{*}$ \\
\hline Equal & $95(60.9)$ & $50(64.1)$ & $45(57.7)$ & \\
\hline Slightly smaller & $43(27.6)$ & $19(24.4)$ & $24(30.8)$ & \\
\hline Much smaller & $15(9.6)$ & $9(11.5)$ & $6(7.7)$ & \\
\hline A bit bigger & $3(1.9)$ & $0(0.0)$ & $3(3.8)$ & \\
\hline In social isolation & & & & $0.383^{* *}$ \\
\hline Yes & $144(92.3)$ & 73 (93.6) & $71(91.0)$ & \\
\hline No & $12(7.7)$ & $5(6.4)$ & $7(9.0)$ & \\
\hline \multicolumn{5}{|l|}{ Symptom that bothers most } \\
\hline Tremor & $44(28.2)$ & $23(29.5)$ & $21(26.9)$ & $0.136^{*}$ \\
\hline Rigidity & $46(29.5)$ & $27(34.6)$ & $19(24.4)$ & \\
\hline Bradykinesia & $23(14.7)$ & $6(7.7)$ & $17(21.8)$ & \\
\hline Gait difficulties & $36(23.1)$ & $19(24.4)$ & $17(21.8)$ & \\
\hline Freezing of gait & $7(4.5)$ & $3(3.8)$ & $4(5.1)$ & \\
\hline
\end{tabular}

Source: PD = Parkinson's disease; ${ }^{*}$ Chi-square test; ${ }^{* *}$ Fisher's exact $(\mathrm{p} \leq 0.05)$

In Table 2, when analyzing the level of PA before the pandemic, most women considered themselves active (41\%); however, during isolation there was a reduction in the practice of PA and these were considered to be little active (49\%). Regarding males, it is observed that before the COVID-19 pandemic, men were not very active (42\%) and still increased slightly during social isolation (59\%).

As for the practice of PA before isolation, most participants practiced some type of PA, with statisti- 
cal difference between genders. In addition, they participate in some specific program for PD during the COVID-19 pandemic. The most practiced activity among women was dancing (33\%) and in men was walking (28\%).

Table 2 - PA practice before and during the social isolation period of the COVID-19 pandemic of individuals with PD according to sex.

\begin{tabular}{|c|c|c|c|c|}
\hline Variables & $\begin{array}{l}\text { Total } \\
(\%)\end{array}$ & $\begin{array}{c}\text { Female } \\
(\%)\end{array}$ & $\begin{array}{l}\text { Male } \\
(\%)\end{array}$ & $\mathrm{p}$ value \\
\hline PA level before & & & & $0.271^{*}$ \\
\hline Sedentary & 13.5 & 17.9 & 9.0 & \\
\hline Little active & 37.8 & 33.3 & 42.3 & \\
\hline Active & 39.1 & 41.0 & 37.2 & \\
\hline Very active & 9.6 & 7.7 & 11.5 & \\
\hline Isolation PA level & & & & 0.594 \\
\hline Sedentary & 25.6 & 29.5 & 21.8 & \\
\hline Little active & 53.8 & 48.7 & 59.0 & \\
\hline Active & 17.3 & 17.9 & 16.7 & \\
\hline Very active & 3.2 & 3.8 & 2.6 & \\
\hline PA practice before & & & & $0.014^{* *}$ \\
\hline Yes & 84.0 & 91.0 & 76.9 & \\
\hline No & 16.0 & 9.0 & 23.1 & \\
\hline Times a week & & & & $0.349^{*}$ \\
\hline 1 to 2 times & 37.4 & 36.7 & 38.0 & \\
\hline 3 to 4 times & 35.9 & 41.7 & 31.0 & \\
\hline 5 times or more & 26.7 & 21.7 & 31.0 & \\
\hline What activity? & & & & $0.068^{*}$ \\
\hline Dance & 23.1 & 33.3 & 12.8 & \\
\hline Fitness & 6.4 & 5.1 & 7.7 & \\
\hline Walking & 21.8 & 15.4 & 28.2 & \\
\hline Bodybuilding & 12.2 & 10.3 & 14.1 & \\
\hline Pilates & 17.9 & 19.2 & 16.7 & \\
\hline Water activities & 8.3 & 6.4 & 10.1 & \\
\hline Other & 10.3 & 10.3 & 10.3 & \\
\hline $\begin{array}{l}\text { Did you participate in a } \\
\text { program for PD? }\end{array}$ & & & & $0.245^{* *}$ \\
\hline Yes & 68.6 & 65.4 & 71.8 & \\
\hline No & 31.4 & 34.6 & 28.2 & \\
\hline
\end{tabular}

Source: PA = physical activity; PD = Parkinson's disease; ${ }^{*}$ Chisquare test. ${ }^{* *}$ Fisher's exact $(\mathrm{p} \leq 0.05)$.

It is important to highlight in Table 3 that most women did not receive guidelines for online practice, unlike men who received from trained professionals (Physical Educators and Physiotherapists). Still, when asked if these individuals like to practice PA online, $80 \%$ answered yes, from which $58 \%$ of women and $51 \%$ of men prefer to practice remotely-guide PA. Regarding the preference for the type of PA during isolation, individuals with PD of both sexes chose dance, being women 59\% and men 47\%, respectively.
It is noted that most of the sample found it difficulty to perform PA in this format (women $74 \%$ and men $68 \%$ ). Of those who responded positively, they reported that the greatest difficulties encountered were in relation to fear of falling and not knowing how to use the tool. With regard to what they liked most about online activities, issues such as not leaving home and being safe were the most listed.

Table 3 - Online PA practice during the period of social isolation of the COVID-19 pandemic of individuals with PD according to sex.

\begin{tabular}{lcccc}
\hline Variables & $\begin{array}{c}\text { Total } \\
(\%)\end{array}$ & $\begin{array}{c}\text { Female } \\
(\%)\end{array}$ & $\begin{array}{c}\text { Male } \\
(\%)\end{array}$ & p value \\
\hline Online PA practice guidance & & & & $0.168^{* *}$ \\
$\quad$ Yes & 49.4 & 44.9 & 53.8 & \\
$\quad$ No & 50.6 & 55.1 & 46.2 & \\
Enjoy the practice of online PA & & & & $0.578^{* *}$ \\
$\quad$ Yes & 79.5 & 79.5 & 79.5 & \\
No & 20.5 & 20.5 & 20.5 &
\end{tabular}

Preference for PA practice

Online

Presential

Type of PA practiced

Dance

Fitness

Walking

Bodybuilding

Pilates

Others

Difficulty of online PA

Yes

No

Reason for the difficulty

Fear of falling

I do not know how to use it

I don't have a good connection

Other

I performed without difficulties$$
5
$$

$\begin{array}{lll}54.5 & 57.7 & 51.3 \\ 45.5 & 42.3 & 48.7\end{array}$

$0.260^{* *}$ 1.3

Attractiveness of online PA

\begin{tabular}{lcccc} 
Don't leave home & 22.1 & 28.6 & 16.7 & \\
Be sure & 29.9 & 28.6 & 31.0 & \\
Doing PA online with family & 3.9 & 5.7 & 2.4 & \\
New technologies & 10.4 & 11.4 & 9.5 & \\
Other & 33.8 & 25.7 & 40.5 & \\
Recommend online PA & & & & $0.420^{* *}$ \\
Yes & 80.8 & 79.5 & 82.1 & \\
No & 19.2 & 20.5 & 17.9 & \\
\hline
\end{tabular}

Source: PA = physical activity; $\mathrm{PD}=$ Parkinson's disease; * Chisquare test. ${ }^{* *}$ Fisher's exact $(\mathrm{p} \leq 0.05)$.

It was found in table 4 that both in the crude analysis $(p<0.001)$ and in the adjusted analysis $(p=0.004)$ 
individuals who were insufficiently active before the pandemic were more likely to remain insufficiently active during social isolation, when compared to individuals who were active previously. Similar to this result, in the crude analysis it is observed that individuals who did not practice PA before isolation presented an almost 5 times greater chance of being insufficiently active than those who already practiced PA $(\mathrm{p}=0.003)$.

In addition, those who performed PA 1 to 4 times a week were more likely to be insufficiently active when compared to those who practice 5 times or more a week. Still, it was observed that those who participated in specific PA programs for PD were less likely to be insufficiently active $(p=0.036)$, as well as individuals who received online guidance $(\mathrm{p}=0.020)$. Finally, it is noted that individuals who preferred to perform PA online was 2 times more likely to be insufficiently active in the crude analysis, when compared to those who preferred face-to-face classes $(\mathrm{p}=0.007)$.

\section{Discussion}

The main objective of this study was to investigate the practice of $\mathrm{PA}$, according to sex, in individuals with $\mathrm{PD}$ in social isolation before and during the COVID-19 pandemic. Thus, it was noticed that most women who considered themselves active before social isolation, became less active during isolation. While men, they remained little active before and during social isolation. In addition, individuals who were insufficiently active before the pandemic were more likely to remain insuf-

Table 4 - Binary Logistic Regression Analysis for the odds ratio of physical activity level before the period of social isolation of the COVID-19 pandemic in individuals with PD.

\begin{tabular}{|c|c|c|c|c|}
\hline Variables & $\begin{array}{l}\text { OR crude } \\
\text { (CI95\%) }\end{array}$ & $\mathrm{p}$ value & $\begin{array}{c}\text { OR adjusted } \\
(\mathrm{CI} 95 \%)\end{array}$ & $\mathrm{p}$ value \\
\hline Sex & & 0.821 & & \\
\hline Female & 1.00 & & - & \\
\hline Male & $1.000(0.534-1.874)$ & & - & \\
\hline Isolation PA level & & $\leq 0.001^{*}$ & & $0.001^{*}$ \\
\hline Insufficiently active & $15.83(4.570-54.88)$ & & $16.46(3.250-83.38)$ & \\
\hline Active & 1.00 & & 1.00 & \\
\hline Is in isolation & & 0.490 & & \\
\hline Yes & 1.00 & & - & \\
\hline No & $0.657(0.199-2.167)$ & & - & \\
\hline Practiced PA & & $0.003^{*}$ & & 0.324 \\
\hline Yes & 1.00 & & 1.00 & \\
\hline No & $4.733(1.676-13.37)$ & & $3.700(1.278-10.71)$ & \\
\hline Times a week & & $\leq 0.001^{*}$ & & $0.004^{*}$ \\
\hline 1 to 2 times & $6.250(2.393-16.32)$ & & $3.307(1.099-9.954)$ & \\
\hline 3 to 4 times & $1.172(0.450-3.048)$ & & $0.684(0.225-2.080)$ & \\
\hline 5 times or more & 1.00 & & 1.00 & \\
\hline Participated in classroom programs & & $0.078^{*}$ & & $0.036^{*}$ \\
\hline Yes & 1.00 & & 1.00 & \\
\hline No & $1.27(0.272-1.073)$ & & $0.372(0.148-0.936)$ & \\
\hline Online guidance & & $0.003^{*}$ & & $0.020^{*}$ \\
\hline Yes & 1.00 & & 1.00 & \\
\hline No & $2.701(1.414-5.161)$ & & $2.901(1.187-7.089)$ & \\
\hline Likes PA online & & 0.567 & & \\
\hline Yes & 1.00 & & - & \\
\hline No & $0.801(0.368-1.745)$ & & - & \\
\hline Prefer online PA & & $0.007^{*}$ & & 0.923 \\
\hline Yes & $2.420(1.269-4.615)$ & & $1.135(0.086-14.90)$ & \\
\hline No & 1.00 & & 1.00 & \\
\hline Recommend online PA & & 0.876 & & \\
\hline Yes & 1.00 & & - & \\
\hline No & $0.938(0.423-2.081)$ & & - & \\
\hline
\end{tabular}

Source: $\mathrm{PA}=$ physical activity; $\mathrm{PD}=$ Parkinson's disease; $\mathrm{OR}=$ odds ratio; $\mathrm{CI} 95 \%$ = confidence interval; ${ }^{*} \mathrm{p} \leq 0.05$ 
ficiently active during social isolation when compared to individuals who were active. Additionally, those who performed PA one to four times a week are more likely to be insufficiently active when compared to those who practiced five times or more a week. Since those who participated in specific PA programs for PD were less likely to be insufficiently active, as are individuals who receive online guidance.

Thus, these results raise important questions to be discussed, as it is noted that the measures of social isolation due to COVID-19 had a negative effect on the physical health of people with confined PD. In addition, the fact that individuals are becoming less active during social isolation contributes to the loss of muscle mass, lack of joint mobility, difficulties in walking, balance, increased pain, in addition to favoring increased stress, anxiety and depressive symptoms, as a consequence worsening quality of life $\mathrm{1}^{10,21,22}$. However, despite the recommendations for social isolation, PA can be performed at this time in the home environment ${ }^{8,18}$. In this study, it was observed that individuals decreased the frequency of PA when compared before the pandemic. Similar results were also found in the study by Ammar et al. $(2020)^{23}$, in which they evaluated 1047 people from different countries during social isolation, in which they dramatically increased the sitting time and decreased the level of PA.

In addition, the results of this study illustrate that individuals with PD who were physically active before isolation were less likely to become insufficiently active, unlike individuals who were inactive. Lesser and Nienhuis ${ }^{24}$ showed similar results in which individuals who were active before the pandemic were more likely to maintain their levels of PA during social isolation, and still reported lower levels of anxiety and stress than individuals who were inactive and remained inactive. In the literature, other studies with different populations have shown similar results ${ }^{21,23,25}$. These are worrying data, as it is known that sedentary behavior contributes to numerous illnesses and also mortality.

It is noticed that it is not simple to maintain the levels of PA while being in isolation at home, especially when it comes to older adults individuals with a neurodegenerative disease such as PD. WHO recommends that to remain physically active during isolation, it is necessary to follow PA classes online, using videos and applications ${ }^{3}$. In this study, most of the interviewees were doing PA online / remotely, however, $71 \%$ say they have some kind of difficulty in taking these class- es, which may be related to the fact that they do not know how to use the tool, a good connection and the fear of falling, which can lead to more severe injuries. Therefore, it is noted that these factors can also contribute to low adherence to online classes and physical inactivity. In a study carried out in France the results were similar, in which there is some resistance and difficulty on the part of the older adults to practice PA online and to learn and use technological tools ${ }^{26}$.

It should be considered that online classes are currently essential to reduce the feeling of social isolation, as well as providing comfort and security for people who live with PD at that time isolated in their homes. In this study, dance classes were reported to be the most practiced before and after the pandemic. For many years, dance has been considered a beneficial activity for individuals with $\mathrm{PD}$, and can act directly to improve motor symptoms (balance, mobility, gait, postural instability), as well as, in non-motor symptoms (depression, mood , cognition, sleep quality, quality of life $)^{27,28}$. Home dance programs are already found in the literature, before the COVID-19 pandemic, and demonstrate excellent results in individuals with $\mathrm{PD}$, in which they work to improve quality of life, balance and functional mobility ${ }^{29}$. In addition to the possibility of conducting online classes in a reduced space, another factor that may explain the choice of dance as more practiced among PAs, is the motivational character with additional impact especially in the period of social isolation ${ }^{30}$.

The study has some limitations, such as the cross-sectional design, as no causality can be inferred. And because the questionnaires were self-administered, which can bias the correct data. Finally, the relatively low number of participants in some Brazilian regions can be considered a limitation. However, our findings alert and indicate the need to practice PA even during the pandemic. The use of technological resources is already considered a safe and beneficial strategy for people with PD and may be a viable method to help increase practice at home. Also, in view of the advance of social isolation in Brazil, health professionals have an important role in providing guidance for the practice of PA.

In conclusion, the results of this study indicate a negative effect of social isolation on PA parameters in individuals with PD. Strategies for health promotion in order to increase PA levels at home, targeting the population with $\mathrm{PD}$, are necessary to reduce the sedentary lifestyle in order to avoid harm to this population during and after the COVID-19 pandemic . 


\section{Conflict of interest}

The authors declare no conflict of interest.

\section{Funding}

This work was carried out with the support of the Coordenação de Aperfeiçoamento de Pessoal de Nivel Superior - Brasil (CAPES) Código de Financiamento 001.

\section{Author's contributions}

Moratelli J and Guimarães ACA participated in the design of the manuscript, analysis and interpretation of data. Sonza A, Haas NA and Peyré-Tartaruga LA carried out the writing of the manuscript and critical review of the content. Passos-Monteiro E, Delabary MS and Correa CL participated in the design of the manuscript and critical review of the content.

\section{References}

1. Nishiura H, Jung SM, Linton NM, Kinoshita R, Yang Y, Hayashi K, et al. The Extent of Transmission of Novel Coronavirus in Wuhan, China, 2020. J Clin Med. 2020;9(2):330.

2. Nascimento IJBD, Cacic N, Abdulazeem HM, Von Groote TC, Jayarajah U, Weerasekara I, et al. Novel Coronavirus Infection (COVID-19) in Humans: A Scoping Review and Meta-Analysis. J Clin Med. 2020;9:941.

3. World Health Organization. (WHO). Novel Coronavirus (2019-nCoV): Situation Report-19. [Cited in 2020 Jul 20]. Available at: https://www.who.int/docs/default-source/ coronaviruse/situation-reports/20200208-sitrep-19-cov. pdf?sfvrsn=6e091ce6_2.

4. Brasil. Ministério da Saúde do Brasil. O que você precisa saber o Corona Vírus. [Cited in 20/07/2020] Availa-ble in:https://coronavirus.saude.gov.br/.

5. Bhidayasiri R, Virameteekul S, Kim JM, Pal PK, Chung SJ. COVID-19: An Early Review of Its Global Im-pact and Considerations for Parkinson's Disease Patient Care. J Mov Disord. 2020;13(2):105-14.

6. KooJR, Cook AR, Park M,Sun, Y,Sun H,Lim J.Interventions to mitigate early spread of SARS-CoV-2 in Singapore: A modelling study. Lancet Infect Dis. 2020;20(6):678-88.

7. Prasad S, Holla VV, Neeraja K, Surisetti BK, Kamble N, Yadav $\mathrm{R}$, et al. Parkinson's Disease and COVID-19: Perceptions and Implications in Patients and Caregivers. Mov Disord. 2020;35(6):912-4.

8. Wang C, Pan R, Wan X, Tan Y, Xu L, Ho C, et al. Immediate Psychological Responses and Associated Fac-tors during the Initial Stage of the 2019 Coronavirus Disease (COVID-19) Epidemic among the General Population in China. Int J Environ Res Public Health. 2020;17(5):1729.

9. Helmich RC, Bloem BR. The Impact of the COVID-19 Pandemic on Parkinson's Disease: Hidden Sorrows and Emerging Opportunities. J Park Dis. 2020:10:351-4.

10. Stella MP, Brundin P, Fung VSC, Kang UJ, Burn DJ, Colosimo C, et al. Impact of the COVID -19 Pandemic on Parkinson's Disease and Movement Disorders. Mov Disord. 2020;35(5):711-15.
11. Jin X, Wang L, Liu S, Zhu L, Loprinzi PD, Fan X. The Impact of Mind-body Exercises on Motor Function, Depressive Symptoms, and Quality of Life in Parkinson's Disease: A Systematic Review and Meta-analysis. Int J Environ Res Public Health. 2019;17(1):31.

12. Cancela JM, Mollinedo I, Montalvo S, Vila Suárez ME. Effects of a High-Intensity Progressive-Cycle Program on Quality of Life and Motor Symptomatology in a Parkinson's Disease Population: A Pilot Randomized Con-trolled Trial. Rejuvenation Res. 2020.

13. Souza Filho BAB, Tritany, EF. COVID-19: importância das novas tecnologias para a prática de atividades físicas como estratégia de saúde pública. Cad Saúde Pública. 2020;36(5):e00054420.

14. Tate DF, Lyons EJ, Valle CG. High-tech tools for exercise motivation: use and role of technologies such as the internet, mobile applications, social media, and video games. Diabetes Spectr. 2015;28(1):45-54.

15. Flynn A, Allen NE, Dennis S, Canning CG, Preston E. Home-based prescribed exercise improves balance-related activities in people with Parkinson's disease and has benefits similar to centre-based exercise: a system-atic review. J Physiother. 2019;65(4):189-99.

16. Khuzema A, Brammatha A, Arul Selvan V. Effect of homebased Tai Chi, Yoga or conventional balance exer-cise on functional balance and mobility among persons with idiopathic Parkinson's disease: An experimental study. Hong Kong Physiother J. 2020;40(1):39-49.

17. Artino AR, La Rochelle JS, Dezee KJ, Gehlbach, H. Developing questionnaires for educational research: AMEE Guide No. 87. Med Teach. 2014;36(6),463-74.

18. Sá-Caputo DC, Taiar R, Seixas A, Sanudo B, Sonza A, Bernardo-Filho M. A Proposal of Physical Performance Tests Adapted as Home Workout Options during the COVID-19 Pandemic. Appl Sci. 2020;10:4755.

19. Rayhan RU, Zheng Y, Uddin E, Timbol C, Adewuyi O, Baraniuk JN. Administer and collect medical ques-tionnaires with Google documents: a simple, safe, and free system. Appl Med Inform. 2013;33(3):12-21.

20. Cicchetti DV. Guidelines, criteria, and rules of thumb for evaluating normed and standardized assessment in-struments in psychology. Psychol Assess. 1994;6(4):284-90.

21. Stanton R, To QG, Khalesi S, Williams SL, Alley SJ, Thwaite TL, et al. Depression, Anxiety and Stress dur-ing COVID-19: Associations with Changes in Physical Activity, Sleep, Tobacco and Alcohol Use in Australian Adults. Int J Environ Res Public Health. 2020;17:4065.

22. Narici M, De Vito G, Franchi M, Paoli A, Moro T, Marcolin $\mathrm{G}$, et al. Impact of sedentarism due to the COVID-19 home confinement on neuromuscular, cardiovascular and metabolic health: Physiological and pathophysiological implications and recommendations for physical and nutritional countermeasures. Eur J Sport Sci. 2020;1-22.

23. Ammar A, Brach M, Trabelsi K, Chtourou H, Boukhris O, Masmoudi L, et al. Effects of COVID-19 Home Confinement on Eating Behaviour and Physical Activity: Results of the ECLB-COVID19 International Online Survey. Nutrients. 2020;12(6):E1583.

24. Lesser IA, Nienhuis CP. The Impact of COVID-19 on Physical Activity Behavior and Well-Being of Canadi-ans. Int J Environ Res Public Health. 2020;17(11):3899.

25. Schuch F, Bulzing R, Meyer J, López-Sánchez GF, Grabovac I, Willeit $\mathrm{P}$, et al. Moderate to vigorous physical activity and sedentary behavior change in self 2 isolating adults during the COVID-19 pandemic in Brazil: A cross-sectional survey 3 exploring correlates. Sport Sci Health. 2020;5:1-9. 
26. Goethals L, Barth N, Guyot J, Hupin D, Celarier T, Bongue B. Impact of Home Quarantine on Physical Activity Among Older Adults Living at Home During the COVID-19 Pandemic: Qualitative Interview Study. JMIR Aging. 2020;3(1):e19007.

27. Kalyani HHN, Sullivan K, Moyle G, Brauer S, Jeffrey ER, Roeder L, et al. Effects of Dance on Gait, Cogni-tion, and Dual-Tasking in Parkinson's Disease: A Systematic Review and Meta-Analysis. J Parkinsons Dis. 2019;9(2):335-49.

28. Tang L, Fang Y, Yin J. The effects of exercise interventions on Parkinson's disease: A Bayesian network meta-analysis. J Clin Neurosci. 2019;70:47-54.
29. Albani G, Veneziano G, Lunardon C, Vinci C, Daniele A, Cossa F, et al. Feasibility of home exercises to en-hance the benefits of tango dancing in people with Parkinson's disease. Complement Ther Med. 2019;42:233-9.

30. Holmes EA, O'Connor RC, Perry VH, Tracey I, Wessely S, Arseneault L, et al. Multidisciplinary research priorities for the COVID-19 pandemic: a call for action for mental health science. The Lancet Psychiatry. 2020;7:547-60.

Received: $13 / 07 / 2021$

Approved: 17/12/2021

Quote this article as:

Moratelli J, Sonza A, Haas AN, Passos-Monteiro E, Corrêa CL, Peyré-Tartaruga LA, Delabary MS, Guimarães ACA. Physical activity of individuals with Parkinson's in social isolation before and during the pandemic COVID-19. Rev Bras Ativ Fis Saúde. 2021;26:e0237.

DOI: $10.12820 /$ rbafs. $26 e 0237$ 